\title{
A complex systems view of climate and development issues in South African coal power expansion
}

\author{
E. Tyler*1미 B. Cohen ${ }^{2}$ \\ 1 Energy Research Centre and African Climate and Development Institute, University of Cape Town, Cape \\ Town, South Africa \\ 2 Department of Chemical Engineering, University of Cape Town, Cape Town South Africa
}

\begin{abstract}
The implementation of climate change policy in South Africa inevitably requires decision-makers to navigate issues of development. This paper explores some of the implications of this requirement by examining the case of a proposed new independent coal-fired power producing plant, Khanyisa, in the province of Mpumalanga from the perspective of complexity studies, an emerging transdisciplinary field. Complexity thinking re-casts the Khanyisa project in a whole-system view, encouraging an active consideration of scale, perspectives, different knowledges, and cumulative impacts. In so doing, tensions both between and within dimensions of climate mitigation and development are quickly revealed, a complexity which is theorised in complexity studies as the raw material for systemic transformation. This wholesystem conceptualisation also undermines incremental and relative arguments that Khanyisa mitigates greenhouse gas emissions. Further, the complex systemic property of non-linearity suggests that the Khanyisa decision is more significant than its power generation capacity indicates. Attention to the conceptual simplification inherent in 'development' highlights what is lost through such simplification, as well as what is gained, and by whom. Finally, complexity thinking foregrounds the multiple scales at which the systemic climate mitigation and development implications of Khanyisa play out. Currently there is very little policy-making capacity nationally, regionally or in eMalahleni to look at alternatives, or 'spaces of possibility' through the complexity lens for both development and climate mitigation. This case argues that new policy processes are needed, which go far beyond policy and regulatory processes steeped in path dependencies and incrementalism.
\end{abstract}

Keywords: complexity studies; climate mitigation; social justice, coal-fired power, electricity sector

\section{Highlights}

- The case reveals the complex entanglement of climate and development issues as raw material for systemic transformation.

- A whole system and scalar conceptualisation, paying attention to non-linearities, and the exercise of power through simplifications suggest productive areas of focus for policymakers

- New policy processes are needed, which go far beyond policy and regulatory processes steeped in path dependencies and incrementalism.

Journal of Energy in Southern Africa 32(1): 1-13

DOI: http://dx.doi.org/10.17159/2413-3051/2021/v32i1a9052

This work is licensed under a Creative Commons Attribution-ShareAlike 4.0 International Licence Published by the University of Cape Town ISSN: 2413-3051 https://journals.assaf.org.za/jesa Sponsored by the Department of Science and Innovation

* Corresponding author: emily.tyler@uct.ac.za, Tel: +27 722255619 


\section{Introduction}

The South African climate change response white paper (NCCRWP) describes the country's mitigation policy objective as being to:

manage the transition to a climateresilient, equitable and internationally competitive lower-carbon economy and society in a manner that simultaneously addresses South Africa's over-riding national priorities for sustainable development, job creation, improved public and environmental health, poverty eradication, and social equality. (Republic of South Africa [RSA], 2011: 11).

This objective is simply stated, underplaying the complexity of the decision-making required to realise it. This paper explores this complexity in the electricity sector, which has been identified as a key source of cost-efficient climate mitigation opportunities for South Africa (McCall et al., 2019), through the case of the Khanyisa project, one of the proposed new coal independent power producers (IPPs). An empirical description of Khanyisa's possible climate mitigation and development impacts from local, urban and national perspectives is developed, using desktop review and stakeholder interviews. Because this description is marked by complexity and competing rationalities operating at different scales, the emerging transdisciplinary field of complexity studies is then used in the second half of the article to further explore the implications of Khanyisa for implementing climate mitigation policy. The paper concludes by reflecting on implications of the analysis for advancing climate mitigation and development objectives in practice.

\section{The coal baseload IPP programme and the Khanyisa project}

South Africa enjoyed decades of low-cost, coal-powered electricity supply from the national power utility, Eskom. This situation changed with the 2007/8 electricity supply crisis, driven largely by a growing economy and underinvestment in generation capacity. The immediate response was to commission two of the largest coal-fired power plants in the world: Medupi in Limpopo province and Kusile in Mpumalanga. These add to Eskom's existing fleet of fourteen coal-fired power plants, most of which are in Mpumalanga, on the Central Basin coal resource.

As a further response to the supply crisis, government initiated a number of programmes to support IPPs, including the suc- cessful and internationally acclaimed Renewable Energy IPP Procurement Programme (REIPPPP) (Fourie, Kritzinger-van Niekerk, \& $\mathrm{Nel}, 2015$, Yuen, 2014) which has signed 102 projects to date (Department of Minerals and Energy [DMRE], undated). A further programme seeks to procure additional coalfired electricity generation capacity, the Coal Baseload IPP Programme (hereafter Coal IPPP), to contribute to baseload power supply, with two projects having been awarded to sell power to the grid - Thabametsi in Limpopo (557MW) and Khanyisa in Mpumalanga (306MW) (DoE, 2015) - although neither has managed to reach financial close.

The Khanyisa site is greenfield land belonging to the mining company Anglo American, $10 \mathrm{~km}$ south of eMalahleni in Mpumalanga (see Figure 1). Mpumalanga lies to the east of Gauteng, South Africa's economic hub. eMahlaleni, 'the place of coal', is in the Central Coal Basin, with the highest concentration of coal mines in South Africa (eMalahleni Local Municipality, 2017). Mpumalanga accounts for $83 \%$ of South Africa's coal production (Ptsera, 2011). Mining has experienced stagnation over the past decade, contributing to social instability in the province (Ptsera, 2011, Siyongwana \& Shabalala, 2018). In eMahlaleni, social issues abound: provision of potable water and electricity supply is constrained, and there is a severe housing backlog (Ptsera, 2011). The district's Gini co-efficient was $0.62 \%$ (above the national average) in 2011 (eMalahleni Local Municipality, 2017).

Khanyisa was originally a project of Anglo American, which intended to supply power to its nearby platinum plant (ACWA Power, 2017). In 2012, ACWA Power, a Saudi Arabian water and power company (www.acwapower.com), was selected by Anglo as a preferred development partner for the project. Towards the end of 2013, due to the slump in global commodities markets (Govender, personal communication, 2018) and a shift in strategic direction (ACWA Power, 2017), Anglo decided to put Khanyisa on hold. When government announced the Coal IPPP, ACWA, in consultation with Anglo, submitted a bid for Khanyisa to be included as a $306 \mathrm{MW}$ grid-connected plant, a bid subsequently won in October 2016 (Govender, personal communication, 2018). This success allocates a power purchase agreement (PPA) for a period of thirty years. In 2015, ACWA submitted an environmental authorisation (EA) amendment report applying for, amongst others, the amendment of 


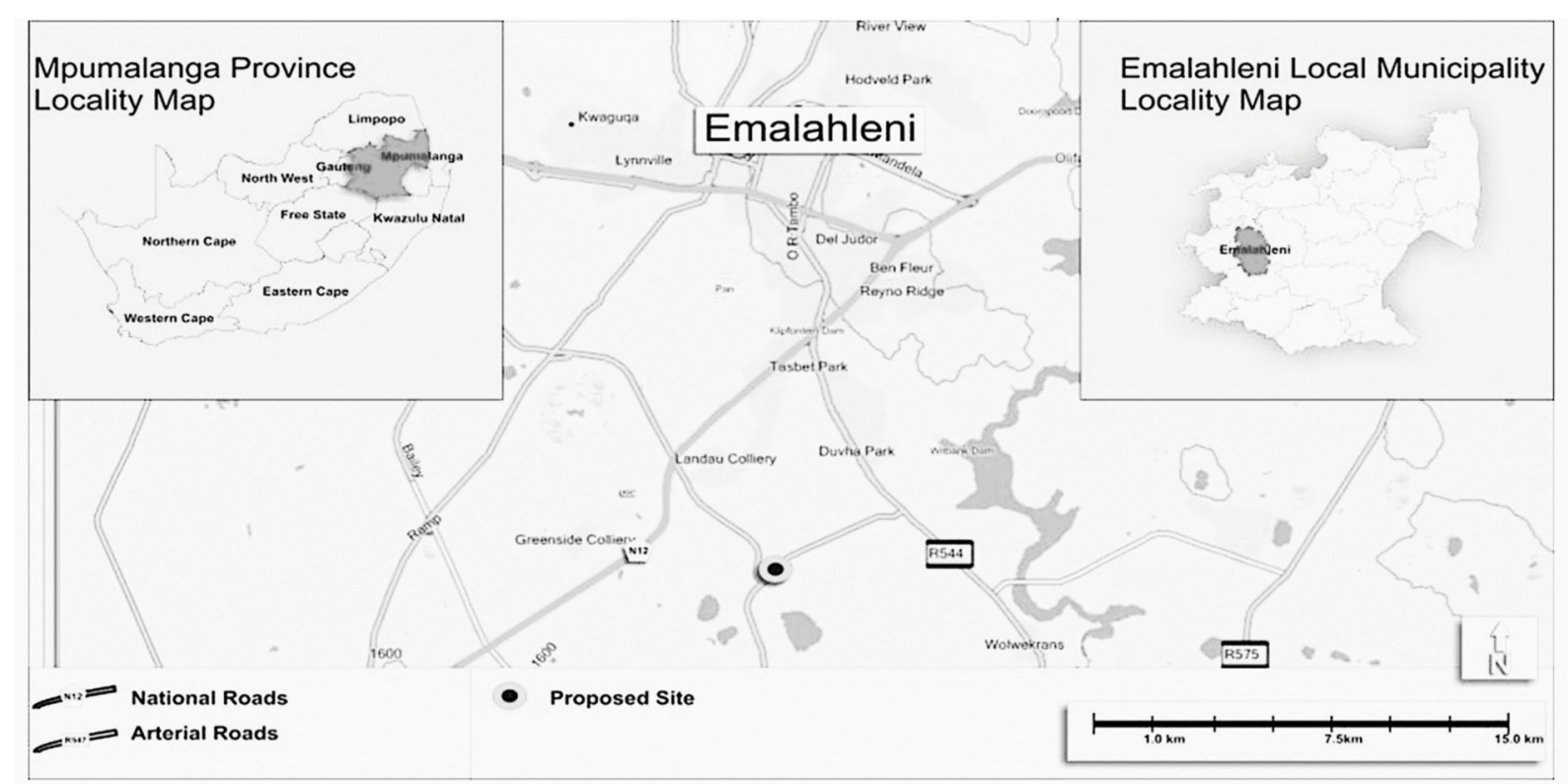

Figure 1: Map showing the location of Khanyisa power station (Aurecon, 2015).

the EA to $600 \mathrm{MW}$ to increase power sales sold onto the grid or privately. The amendments were approved (DEA, 2015; DEA, 2017).

Geotechnical drilling has been undertaken to confirm site feasibility, as has some site development and preparation (ACWA Power, 2017). Otherwise, the project remains on paper, with ACWA working to achieve an investment decision. Whilst this was expected to have occurred in 2017 (ACWA Power, 2017), at the time of writing various licences remain outstanding or subject to appeal and legal challenge (Global Energy Monitor Wiki, accessed 2020).

ACWA Power holds the primary equity stake of $40 \%$, which is project-financed (ACWA Power, 2017). Local companies Thebe Investments, Pele Natural Energy, Hulisani Capital, and Palace Group each hold a minority stake (ACWA Power, flyer n.d.), together accounting for $37 \%$ of the value (Engineering News, 11 November 2016). Debt finance will be provided by the Industrial Development Corporation - R1.2 billion, 25.3\% of total project cost $^{1}$ (Engineering News, 10 November, 2016) - and major private South African banks, although many have been pulling out of the project including in response to the global coal divestment movement, putting the ability of the project to reach financial close in jeopardy (Global Energy Monitoring Wiki, 2020). ACWA and Palace will operate the project together (ACWA Power, undated), with General Electric being identified as the engineering, procurement and construction contractor (ACWA power, 2017).
Khanyisa envisages utilising discard coal to generate power through the use of circulating fluidised bed (CFB) boiler technology. This is the first time CFB is being used in South Africa (ACWA power, 2017; Engineering News, 11 November 2016). Because discard coal is too poor quality for export or use in the Eskom fleet (Govender personal communication, 2018) it is maintained in coal heaps that, if left unmanaged, pollute groundwater and possibly the air (Bian et al, 2010; Laisani \& Jegede, 2019). Anglo's nearby KleinKopje and Greenside collieries will supply the coal.

\section{How might Khanyisa impact development?}

'Development' is a highly simplified concept, with multiple dimensions, including those highlighted by the NCCRWP: sustainability, job creation, health, poverty eradication, and social equality. Different societal stakeholders interpret 'development' in different ways. Khanyisa's supporters argue that it will positively impact development framed in terms of employment, energy security (IPP Office, 2018) and economic growth (Govender, personal communication, 2018; Netch, personal communication, 2018; DoE, 2016). Opponents argue that the project negatively impacts development from the perspective of environmental sustainability, health, poverty eradication and social equality.

Four dimensions of development are considered here, as those which emerged most strongly from the research: 1) employment and local economy related implications, 2) health, 3) redressing historical equality, and 4) 
the role of national power supply. The first two are of greater importance at the local and urban scales, whilst the remaining two have greater resonance nationally. The four dimensions are considered below.

\section{Employment and local socio-economic implications}

Mirroring challenges in assessing and reporting employment in the power sector (Tyler \& Steyn, 2018), there are a number of conflicting employment projections for Khanyisa: the Department of Energy (DoE) (DoE, 2016) shows Khanyisa contributing 4500 jobs during construction and 1300 in operations and maintenance. ACWA only reports local jobs, as 250 during construction and 150 during operation (ACWA Power flyer, n.d.; ACWA Power, 2017). In ACWA's licensing application, a total of 1500 jobs during construction are identified (NERSA application, n.d.). Engineering News (11 November, 2016) identifies 3000 jobs in construction and 150 in operation. The social impact element of the environmental impact assessment (for a 450 MW power project) identified an average of 900 people for construction and 120 during operation (Ptsera, 2011). The extent of variability in these numbers is testament to a lack of reliable data and accountability in its use in the power sector. What are the implications of these varying jobs numbers, especially considering South Africa's unemployment woes? Tyler and Steyn (2018) caution that this situation is abused by those with particular agendas pursuing these through an emotive and misleading national discourse.

The eMalahleni Integrated Development Plan (IDP) (2017) supports electricity generation projects, describing them as key to the local economy, and large projects as important for accessing public infrastructure funding. This is despite links between employment, economic growth, mining and power generation being controversial; eMahlaleni, an urban hub, has been in at the epicentre of the coal economy for 150 years, and has at least $40 \%$ unemployment in its townships (Hallowes, personal communication, 2018). The largest employing industries in eMalahleni are reported as trade and community/ government services (eMalahleni Local Municipality, 2017), not mining or power generation.

Khanyisa's 2011 social impact assessment (Ptsera, 2011) provides indication from social groups affected by the plant that, whilst employment opportunities were identified as being desirable, there were also specific justice- related concerns: Khanyisa would attract skills away from existing jobs in the area due to higher wages from short-term construction contracts; there would be migrants to the area seeking work, and this, together with the excess workforce after the construction phase, would destabilise existing communities. Nearby informal settlements were reported as not wanting another power plant - 'even when all management processes are in place there are still negative effects' (Ptsera, 2011: 37). This ambiguity suggests an inability to imagine alternatives. The employment creation potential of any large capital project should not be considered in isolation, but also from the perspective of alternative applications of that capital. There is a lot of interest in considering the employment creation potential, for example, of renewable energy projects in the Mpumalanga area (TIPS, 2020).

Finally, unemployment and social instability in eMalahleni affects neighbouring Gauteng, as job-seekers migrate to the metropole, putting pressure on urban infrastructure and service provision.

\section{Health}

Coal-fired power generation releases local air pollutants (particulate matter, sulphur dioxide $\left(\mathrm{SO}_{2}\right)$, nitrogen dioxide $\left(\mathrm{NO}_{2}\right)$, and carbon monoxide (CO) (Aurecon, 2012; 2015)), which are linked to heart disease, lung cancer, stroke and chronic obstructive pulmonary disease (Naledzi, 2018). The Highveld Priority Area Air Quality Management Plan suggests that power generation is the primary driver for hospital admissions in Mpumalanga (Groundwork, 2017). Khanyisa's environmental assessments (Aurecon 2012; 2015) found that the project's local air pollution would be within the post-2030 national ambient air quality standard, and with mitigation measures could be reduced to low or very low significance. In response to these EAs, the Department of Environmental Affairs (DEA) issued an integrated environmental authorisation (2012) and amendments (DEA, 2015; DEA, 2017) for Khanyisa, taking the view that if environmental emissions are below the national regulated limits and the proposed environmental management plan is adhered to, then air quality issues are manageable. ACWA describes Khanyisa as employing 'environmental best practice', adhering to World Bank and Equator Principles (ACWA Power flyer, n.d.; Govender, personal communication), resulting in its atmospheric emissions being below both international best 
practice (ACWA Power, 2017), and below South African regulatory requirements (Govender, personal communication, 2018). The project further includes best available emission abatement technologies' (ACWA Power, 2017), including introducing limestone into the boiler to mitigate sulphur emissions.

However, neither the DEA nor ACWA's views take the cumulative impact of local air emissions into account. Khanyisa is located within the Highveld Priority Area, an area "characterised by poor air quality and exceedances of pollutant limits set in South African legislation' (Aurecon, 2015: 14), due to the industrial, power generation and mining activities in the region. Despite mines and power generators having EAs with emissions limits in place, the air quality sub-system continues to be characterised by emissions above the legal limits, particularly in winter (Groundwork 2016, 2017; Aurecon 2015). The EA amendment report admits that 'any contribution resulting from the proposed project would in fact contribute to exceeding the legal concentration levels for the aforementioned pollutants during the winter months' (2015: 21), and 'if uncontrolled, the proposed power station could significantly influence the air quality in the eMalahleni (Witbank) region and further afield' (Aurecon, 2015: 14). The issue of cumulative atmospheric emissions in the area was anticipated to be dealt with by the 2011 Highveld Priority Area air quality management plan. However, the 2015 mid-term review of this plan showed little improvement in the area's ambient air quality (DEA, 2015).

The issue of health also slips between the cracks of the EA process; neither the Khanyisa EA nor its social impact study attempts to quantify its local health impacts. Whilst the health implications of elevated atmospheric pollutants are detailed in the EA, this attention is not carried through in the social impact report, which merely identifies the increased incidence of air quality health challenges in vulnerable groups such as children, those with asthma and the elderly (Ptsera, 2011).

Considering the health dimension of development from a regional perspective reveals an interesting paradox. A significant source of urban local air pollution comes from the use of primary energy sources (coal, kerosene, wood) for lower-income residential energy services, resulting in corresponding respiratory health issues in poor urban areas. These sources of energy are favoured over electricity partly because electricity is expen- sive (Ismail and Khembo, 2015). Air pollution in eMalahleni may be increased, on balance, due to Khanyisa, but there is an argument (considered in further below) that Khanyisa will decrease air pollution in Gauteng.

\section{Redressing historical inequality}

One of the main ways South Africa has attempted to address its racial history is through the government's Broad-Based Black Economic Empowerment (B-BBEE) programme (RSA, 2004). This programme requires a percentage of black ownership across economic activities, with the Coal IPPP having been identified as a vehicle for the policy. Four local B-BBEE-accredited companies are involved in Khanyisa's project finance structure, with effective black ownership in the project greater than 35\% (ACWA power, 2017). ACWA focuses on this dimension of development in its communications. There is a perception within the country that those who benefit from B-BEEE are those with access to a level of education, finance and networks, and are more likely to be located in Gauteng than eMalahleni (Patel \& Graham, 2012).

\section{National power supply}

Maintaining and expanding grid power is deeply embedded in South African policy narratives around development and poverty alleviation (National Planning Commission, 2011), based on the assumptions that grid electricity is the cheapest and cleanest form of electricity. As such, a main feature of the Coal IPPP is to provide increased energy security and contribute towards socio-economic and sustainable growth objectives' (www.ipp-coal.co.za). These assumptions are used by DoE and ACWA to promote Khanyisa's contribution to 'development', specifically that grid electricity is the most affordable, that the grid requires additional baseload power, and that the use of discard coal is a cost-effective way to provide this. ACWA (2017) describes Khanyisa as transferring to South Africa important 'transitional coal beneficiation technology that contributes to a number of South Africa's developmental objectives.

The assumption of a national utility providing lowest-cost electricity via the grid has held for a long period. However, the power sector is now described as being in the midst of a period of disruptive change (BischofNiemz \& Creamer, 2018). Eskom is battling corruption, the terminal decline of the coal sector upon which its business model is based, 
and the early stages of a utility death spiral (where a utility counters falling demand with rising prices), prompting more customers to turn to independent power generation (Steyn, Burton, \& Steenkamp, 2017). Electricity demand has plateaued since the inception of the Coal IPPP due to a combination of economic stagnation and a reduction in energy intensity of economic activity (Ireland \& Burton, 2018), with further impacts of the Covid-19 pandemic on demand being observed, although it is not known what the longer-term implications will be. The rise of urban embedded generation (such as rooftop solar) and international city-level environmental scrutiny (see www.c40.org), is driving tension between metros and national government around the single purchaser model and encouraging those who can afford off-grid solutions to install them. Recent energy modelling now shows both Coal IPPs as being amongst the most expensive power generation options, and that committing to these plants will be negative for the country's economic development (Wright et al., 2017; Ireland \& Burton, 2018). ${ }^{2}$ These changes have influenced, and will continue to influence, the quantity, nature and price of grid electricity, with corresponding implications for climate mitigation and development.

The implications of Khanyisa for other dimensions of development are also tied up with the grid electricity price. As price increases, those who can afford to will turn to off-grid solutions. Collectively this action exacerbates the utility death spiral, further increasing electricity prices for the poor and exacerbating inequality. Electricity revenues for the metros (which achieve a large portion of their municipal budgets through distributing grid electricity) decline, reducing the funds available for urban public services generally, with further negative implications for the poor.

\section{How might Khanyisa impact South Africa's climate mitigation efforts?}

The main contribution of Khanyisa to climate change will be through the release of the greenhouse gases (GHGs) carbon dioxide $\left(\mathrm{CO}_{2}\right)$ and nitrous oxide $\left(\mathrm{N}_{2} \mathrm{O}\right)$ from the burning of discard coal using CFB technology. There will also be GHG emissions from the reaction of limestone, which is being proposed as a mitigation measure for $\mathrm{SO}_{2}$ emissions. ${ }^{3}$ However, based on the Thabametsi climate change study (Savannah Environmental, 2017) limestone emissions are not significant when compared to those from burning coal. Use of discard coal for power gener- ation is argued to avoid GHG emissions released through spontaneous combustion of dormant coal heaps (ACWA Power, 2017), although research in the South African context finds these to be minimal if the coal heap is properly remediated (Cook \& Lloyd, 2012).

ACWA Power argues that Khanyisa's CFB technology offers intrinsically lower emissions' (2018), with $\mathrm{CO}_{2} / \mathrm{MWh}$ lower than the current [Eskom] fleet of older plants' (2017), and as such is an 'important transitional coal beneficiation technology' (2017). Neither the 2012 EIA nor the 2015 EA amendment report considered Khanyisa's GHG emissions in detail, something that was challenged legally by the Centre for Environmental Rights in 2017, following a similar challenge to Thabametsi's EA. ${ }^{4}$ The 2012 EIA, however, states that Khanyisa is likely to contribute about $4.3 \mathrm{Mt} \mathrm{CO}_{2}$ per year. This is based on the assumption of "a $450 \mathrm{MW}$ power station with an emission factor of $1100 \mathrm{~g} \mathrm{CO}_{2}$ per kWh sent out, operating with Flue Gas Desulphurisation on KleinKopje discard for 8700 h per year' (Aurecon, 2012: 199). A $1100 \mathrm{~g}$ emission factor is in line with that of Eskom's less efficient power stations, so this finding does not align with ACWA's 'intrinsically lower emissions' argument.

Recently, the use of the $1100 \mathrm{~g}$ emission factor in the 2012 EIA has been queried by Ireland and Burton (2018), who recommend the use of the factor of $1230 \mathrm{~g}$ calculated by the Environmental Monitoring Group for Thabametsi, which also uses CFB technology (Savannah Environmental, 2017), as this figure is 'the most comprehensively investigated and recent figure accounting for GHG emissions of CFB in South Africa' (Ireland \& Burton, 2018: 11). The difference between the two is due to including $\mathrm{N}_{2} \mathrm{O}$ emissions, significant in CFB as opposed to conventional pulverised fuel coal plants. Including $\mathrm{N}_{2} \mathrm{O}$ emissions renders the GHG emissions of a CFB plant such as Khanyisa '24\% higher than the current Eskom fleet average, and 58\% higher than Medupi and Kusile' (Ireland \& Burton, 2018:11). Ireland and Burton do acknowledge that there may be ways in which a plant like Khanyisa can mitigate $\mathrm{N}_{2} \mathrm{O}$ emissions, although these remain unacknowledged and unaddressed by either ACWA Power or the Khanyisa literature. Khanyisa's GHG emissions appear to be far higher than the latest conventional coal technologies would produce, and certainly than gas-fired power, suggesting that a technology like coal $\mathrm{CFB}$ is hard to justify from a climate mitigation perspective. 
ACWA further claims that the 'Khanyisa GHG emissions are accommodated in the SA National Benchmark Emissions Trajectory' (ACWA power, 2017). This is a reference to the NCCRWP, which specifies a quantified range of acceptable national GHG emissions until 2050 (RSA, 2011). This trajectory range peaks between 2020 and 2025, plateaus for a decade and then declines, and is included in the nationally determined contribution (NDC) submitted under the 2016 Paris Agreement, thus constituting an internationally recognised commitment.

South Africa's emissions are currently within this trajectory range, and projections suggest that the IPP coal power plants will not by themselves cause the country to exceed it (DEA, 2018). However, this requires further interrogation into two aspects. First, whether South Africa's NDC commitment is an adequate contribution to global mitigation efforts. Whilst the upper limit of the trajectory range has been deemed 'inadequate' in meeting the Paris Agreement's goals (Climate Action Tracker, 20195), the lower limit has been described as 'fair' (Marquard, 2019). The NDCs, as a mechanism of the Paris Agreement, are also required to ratchet up in terms of ambition every five years (Voigt, 2016). Second, is the degree of mitigation effort required from the electricity sector to meet the lower trajectory and its increasingly more ambitious interpretations. The policy work to assign proportions of the carbon budget implicit in the trajectory range to various activities (such as power generation) has not yet been concluded. In the 2010 Integrated Resource Plan (IRP), the power sector voluntarily adopted a $275 \mathrm{Mt} \mathrm{CO}_{2} \mathrm{e}$ constraint based on South Africa's international commitments in the Copenhagen Pledge (RSA, 2010). Particularly given the significant subsequent decline in renewable energy power generation costs, the power sector contains the majority of South Africa's least-cost mitigation options and therefore will be needed to do more than what is identified in the 2010 IRP, in order for the country to comply with its Paris Agreement obligations (Tyler, 2020; McCall et al., 2019). Despite the rapidly changing renewables landscape and mitigation imperative, in 2019 an updated IRP was published, which kept the same $275 \mathrm{Mt} \mathrm{CO}_{2} e$ constraint as the 2010 IRP and included both the Thabametsi and Khanyisa coal-fired power stations, although a significant renewable energy programme was included.

The issue of cumulative versus relative impact in the context of local air pollutants is also relevant with regard to GHG emissions, evidenced in the dual focus of the discussion in this section - first with regard to the emissions factor, and then the impact of Khanyisa on the sector's carbon budget. Although no management plans are yet identified for Khanyisa's GHG emissions, adherence to these is questionable in light of the discussion on local air quality.

The discussion in this and the preceding section has highlighted the complex, interconnected and multi-dimensional nature of Khanyisa's potential impact on climate mitigation and development, with a number of themes emerging: (1) The cumulative impact of Khanyisa on climate mitigation is obscured by EA processes and developer rhetoric; (2) Khanyisa's climate mitigation and development implications differ between the different dimensions of each issue (e.g. employment creation and health), across different locations (e.g. eMalahleni and GCR) and across different timeframes (historical and present day injustice); (3) the lack of current and reliable data enables powerful interests to dominate; and (4) high-level conceptual terminology can hide competing rationalities. As such, the discussion evidences the complexities of the climate mitigation and development relationships across the dimensions of society, time and space. The paper now turns to complexity studies to provide a perspective on this.

\section{Applying complexity studies to the Khanyisa case}

The field of complexity studies is represented by nascent theoretical and applied work spread both wide and thin across the academy (for example Cairney \& Geyer, 2015; Chettiparamb, 2014; Kurtz \& Snowden, 2003; Morin, 2006; Price et al., 2015; Walby, 2007; Wells, 2013). There is no 'unifying' theory of complexity (Chu, Strand, \& Fjelland, 2003); it is better understood as a series of perspectives and interpretations drawing from a developing set of concepts and principles. Complexity's origins lie in the natural sciences, but it is being increasingly taken up in other disciplines, including from a transdisciplinary perspective with potential application to issues of sustainability highlighted (Wells, 2013). In response to the themes emerging from the discussion thus far, a few complexity concepts and principles are selected to explore the Khanyisa case. First, the concept of a complex system as an organising frame for considering Khanyisa's climate mitigation and development implications across time 
and scale. Second, the role of research and data using complexity principles. Third, from a complexity paradigm, attention is drawn to the dangers of simplification.

\section{The complex system as an organising concept}

From a complexity view, the universe is both a complex system and is composed of complex systems (Richardson, Cilliers, \& Lissack, 2001). Complex systems are nested within complex systems, and complex systems overlap each other. They can comprise any combination of human, animate and inanimate components. They are inherently uncertain and unpredictable, yet can be recognised through their patterning (Wells, 2013). Complex systems are dynamic, finding stability through constant change (Shine, 2015). Engaging the 'complex system' as a conceptual frame, through which the climate mitigation and development implications of Khanyisa are considered, presents a view that embraces rather than attempts to negate or contain interconnection and complexity.

\section{System dimensions and interconnections}

Systems components relevant to Khanyisa include the typical energy sector concerns of technology, finance and economics as well as those of the humanities and social sciences (history, power, politics and worldviews), societal and cultural knowledges, data, regulations and policy, and even concepts such as climate mitigation and development.

A complex systems view emphasises interconnections between system dimensions, and values revealing these. For Khanyisa, climate mitigation and development cannot operate separately from each other or the system. System dimensions co-determine each other, and co-evolve in response to internal and external change. They are interconnected, both to each other and within their own dimensions. In Khanyisa's case: poor air quality impacts the health of the vulnerable; adding limestone to reduce local atmospheric emissions increases GHG emissions; employment opportunities increase but social stability decreases; it addresses aspects of historical inequity but perpetuates an economic system that drives inequality; it transfers technology that utilises polluting discard coal-heaps, but increases GHG emissions. This messiness is evident, and a source of localised variability that complexity theories suggest provides both systemic stability and the source of change (Boulton, Allen \& Bowman, 2015).

\section{A whole systems view}

A complexity conceptualisation involves taking a whole system view, as opposed to the linear, separate and marginal views of classical disciplinary science and, in particular, its application in economics. This view favours the cumulative perspective on climate mitigation or local air quality above the incremental, highlighting the failure of the DEA's processes to reveal Khanyisa's cumulative environmental impacts and undermining ACWA's appeals to relatively more efficient technology.

\section{Engaging scale}

Complex systems operate at different scales, with Khanyisa's impact on climate mitigation and development playing out across a number of these scales. Khanyisa may worsen health in eMalahleni whilst contributing to health in Gauteng through the provision of electricity. Whilst Khanyisa contributes towards redressing a form of historical injustice at a national economic level, the project may simultaneously exacerbate current local injustices through social instability in eMalahleni. The use of CFB may enable the removal of discard coal-heaps in South Africa, but this activity contributes to global GHG emissions. International agreements and national policy direction have implications for the local scale, and vice versa.

\section{Space and time in complexity}

Complex systems have clearly articulated dimensions of space and time, in contrast to the abstraction that typically occurs under classical science. As regards space, complexity theories state that detailed context specificity determines the local variations that drive both system-wide stability and change. Time in complexity is uni-directional; a system's history determines its future, and the particular patterning that results from this history is relevant to understanding how current events might play out. The South African economic system has developed a central 'minerals and energy complex' (MEC) (Burton, 2011; Fine \& Rustomjee, 1996) 6 over the past century. Deeply entrenched MEC structures feature in South Africa's power generation sector and economy as a result, such as the reliance on coal and large technology solutions. These structures hinder the consideration and uptake of viable alternatives, such as off-grid embedded electricity generation, or the generation of electricity from renewables in combination with storage. Khanyisa is a product of these structures and strengthens them going forward, in a self- 
perpetuating feedback loop, or vicious cycle, typical of complex systems. Similarly, South Africa's persistently high levels of inequality have deep historical roots. Countering these entrenched patterns requires disruptive change of the type currently occurring in the electricity sector, suggesting that this is a window of opportunity for policymakers to support and enable a shift towards more lowcarbon and developmental patterning going forward.

\section{Mechanisms of complex systems: non-linearity and path dependency}

Complex systems are non-linear, prioritising a consideration of how a project such as Khanyisa could initiate or sustain path dependencies. Khanyisa both benefits from South Africa's historical coal path dependency and perpetuates it in a particular form through introducing CFB technology to utilise discard coal, but also through the model of a B-BBEE-empowered project finance structure, and the absorption of a portion of Kusile's labour force once that plant is completed.7 Systemic structure is a significant contributor towards path dependencies in systems, acting as a lag on the system, an inhibitor of change. These path dependencies operate in policy and regulatory processes, locking out the ability to consider alternatives such as utility-scale renewable energy, which may have very different climate mitigation and development implications for both Mpumalanga and Gauteng. Khanyisa introduces long-term physical structure (generating plant, transmission, transport), and institutional structure (the 30 year PPA (ACWA Power, 2017)) into the complex systemic environment, contributing to the carbon-intensive lock-in discussed previously.

A complex view suggests, then, that Khanyisa is most appropriately considered not as a decision about an individual power plant, but rather as about the desirability or otherwise of ushering in a fleet of discard coal-fired power plants. Indeed, this is partially the basis of ACWA Power's argument for the project.

\section{The role of research and data in complexity}

Complex systems cannot be 'known', as any observation of the system is one observation from one perspective at one point in time. What then is the role of data and knowledgemaking in a complexity view? Certainly, research into a system's historical patterning is valuable in order to better understand how the present-day system may respond to events. Data, such as ERM's emissions factor for CFB or Khanyisa's project employment creation, is most valuable to decision-makers at the time of its production, given complexity's emphasis on the particular context in which the data was generated. Data becomes part of the system itself, to influence or be used by other system agents. Access to reliable and timely research and data is also important for decision-makers to be able to respond to the system as it currently is, rather than to an historical version of the system.

A focus on what the system is currently doing (in terms of climate mitigation and development) is also relevant. These issues are powerfully demonstrated in ACWA's appeal to the national emissions benchmark trajectory range and IRP process to legitimate its GHG emissions and power supply impact, despite the current state of the power system and mitigation commitments having moved on. Lack of reliable employment data again demonstrates how path-dependent structures (here the MEC) can use different versions to assert power. Timely information on emissions factors, system modelling, and technology developments have similarly been used by civil society (such as the Centre for Environmental Rights) to resist the project.

\section{The dangers of simplification}

Whilst simplification is necessary to function in complex contexts, complexity theories warn of its dangers. In each instance of simplification, something is lost. Given the importance of context and variation for system resilience (Boulton et al., 2015), simplification actively reduces systemic resilience.

The Khanyisa case engages with conceptual simplification. The terms 'climate mitigation', 'development', 'sustainability', and 'economic growth' are all simplifications. Whilst these hard-won high-level simplified concepts did the work of bringing climate mitigation and development issues onto the political agenda, it is not clear that they are adequate for shifting our complex social systems in an environmentally sustainable and socially just direction. Much has been lost in the attempt to cohere different interest groups around these concepts at a political level. In particular, conceptual simplifications become vehicles for the exercise of power in the system, and may be used to actively resist change. The views of development of government and business, which are based on the assumptions that management plans are implemented and that economic growth is the best path for development, can overwhelm the less 
powerful - including the eMalahleni residents, the Guateng poor, and environmental activists. Aspects of climate mitigation and development are undermined and lost.

Complexity theory suggests that the opposite of simplification is useful: a 'complexification' to regain the local variations that these concepts now hide (Stern, Sovacool, \& Dietz, 2016), to describe and populate the spaces between and within the entanglement of climate mitigation and development. Support for local and contextual experimentation and innovation, for microlevel initiatives, for SMEs, all add diversity and complexification.

\section{Reflections for decision-makers}

The paper conducted an empirical discussion of the implications of the Khanyisa coal-fired power generation plant for the policy objectives of climate mitigation and development. This discussion has revealed the multi-dimensional and complex relationships both between and within the two concepts as they meet in the case, as well as the different temporal and spatial locations where these are held in tension. Complexity thinking provides a particular way of thinking about this complexity that challenges the dominant analytical ideals of simplicity and clarity.

Complexity thinking re-casts the Khanyisa project in a whole-system view, encouraging an active consideration of scale, perspectives, different knowledges, and cumulative impacts. In so doing, the entanglement, messiness and tensions both between and within dimensions of climate mitigation and development are quickly revealed. A whole-system conceptualisation undermines incremental and relative arguments that Khanyisa mitigates GHG emissions. Further, the complex systemic property of non-linearity reveals that the Khanyisa decision is more significant than is suggested by its size, as it both strengthens and expands South Africa's coalfired power path dependency. Attention to the conceptual simplification inherent in 'development' highlights what is lost through such simplification, as well as what is gained, and by whom; for Khanyisa, powerful interests use 'development' to resist systemic change. Complexity thinking foregrounds the multiple scales at which the systemic climate mitigation and development implications of Khanyisa play out. Electricity consumed in Gauteng does not arrive devoid of climate mitigation and development implications at local and national scales, and, similarly, decisions around electricity made within the urban area impact other scales. Currently there is very little capacity or processes nationally, regionally or in eMalahleni with which to look at alternatives, or 'spaces of possibility' through the complexity lens, which foregrounds scale, perspectives, different knowledges and cumulative impacts. So Mpumalanga, the electricity sector, and the country continue to evolve around coal, despite the implications for climate mitigation and development.

The complexity view of Khanyisa and the South African power system raises and prioritises a specific set of questions for decision-makers at various scales: Who is power bought from and at what price? What are the climate mitigation and development implications of this purchase at other scales? What are the implications of going off-grid? What path dependencies are being supported or created through different decisions? What are the cumulative GHG impacts? How does one compare climate mitigation and development implications at different scales? What processes might do better than current EIAs to reveal cumulative and systemic GHG impacts? How does research and data enter the system and influence decision-making? How current is the information about the system? How much do we know of historical patterning? What power-patterning is enabled or sustained through high-level simple concepts? Understanding historical patterns and access to real-time data on the current state of the system becomes a priority in responding to these questions, as does accessing the disciplinary skills of the social sciences (Stern et al., 2016).

Responding to these insights, and exploring rather than avoiding contestation and complexity, may open up new 'spaces of the possible' towards which the system might move, into systemic configurations more closely oriented to both climate mitigation and development. New policy processes are needed, to go far beyond the policy and regulatory processes evident in the case which are steeped in path dependencies and incrementalism.

It could be argued that the empirical evidence is stacked against Khanyisa's contribution towards climate mitigation and development, and that the project may slow down or make the transition to a more just and environmentally sustainable power sector more painful. Having said this, there remains a messiness of competing evidence and indeterminate findings. Whilst uncomfortable, this complexity is also the source of richness and 
variation, which, in complexity studies, is theorised as the raw material for systemic transformation.

\section{Notes}

1. These figures do not sum to $100 \%$, likely because they are derived from different sources.

2. The inclusion of Khanyisa in the generation mix will result in an 'addition in the total discounted [power generation] system cost' across all four of the scenarios, Burton and Ireland considered (2018:2).

3. Limestone $\left(\mathrm{CaCO}_{3}\right)$ is added directly into the plant where it is converted to lime $(\mathrm{CaO})$, releasing $\mathrm{CO}_{2}$. The lime reacts with $\mathrm{SO}_{2}$ to form gypsum, which is a stable product.

4. The case is still pending at the time of writing (Centre for Environmental Rights [CER], 2018).

5. https://climateactiontracker.org/countries/ south-africa/ dated 2 December 2019 accessed 26 May 2020.

6. South Africa's total merchandise exports are $60 \%$, comprising minerals and resources (CCRED, 2018).
7. The construction of Kusile has required a huge labour force, and the plant is coming to the end of its construction phase. Some of this labour is expected to be absorbed in the construction of Khanyisa, only $50 \mathrm{~km}$ from the Kusile site. This may reduce (or delay) some of the anticipated social disruption anticipated from the loss of Kusile's jobs. Whether greater social stability is desirable depends on perspective - destabilisation provides fertile ground for a systemic phase state shift.

\section{Author contributions}

Emily Tyler undertook the primary research, data analysis and drafting of paper. Brett Cohen contributed to paper conceptualisation, and undertook technical editing and review.

\section{Acknowledgement}

This paper is based on a chapter of a Gauteng City Region Conservatory research report which investigated the relationship between environmental sustainability and social justice (forthcoming).

\section{References}

ACWA. Undated. Khanyisa flyer.

ACWA. 2017. Khanyisa IPP phase one, 306 MW Greenfield project. Project overview.

NERSA Application form: ACWA Power Khanyisa Thermal Power Station (RF) (Pty.) Ltd. (Undated). Electricity generation licence application form.

Aurecon. 2015). Environmental Authorisation Amendment Report, Khanyisa Power Station, eMalahleni, Mpumalanga Province. Reference 111415, Revision 1.

Aurecon (2012). Environmental and social impact assessment report: Khanyisa coal fired power station, eMalahleni, Mpumalanga. Volume 1 of 4.

Bian, Z., Inyang, H. I., Daniels, J. L., Otto, F. and Struthers, S. 2010). Environmental issues from coal mining and their solutions. Mining Science and Technology, 20(2): 215-223. http://doi.org/10.1016/S1674-5264(09)60187-3

Bischof-Niemz, T. and Creamer, T. 2018. South Africa's energy transition: A roadmap to a decarbonised, low-cost and job-rich future. Routledge, Oxford, United Kingdom.

Boulton, J., Allen, P. and Bowman, C. 2015. Embracing complexity: Strategic perspectives for an age of turbulence. Oxford University Press. Oxford, United Kingdom.

Burton, J. 2011. The role of industrial policy in pursuing climate change mitigation objectives in South Africa. Energy Research Centre, University of Cape Town, Cape Town, South Africa.

Cairney, P. and Geyer, R. 2015. Introduction. In R. Geyer \& P. Cairney (Eds.), Handbook on complexity and public policy: 1-19. Cheltenham, United Kingdom: Edward Elgar.

Chettiparamb, A. 2014. Complexity theory and planning: Examining 'fractals' for organising policy domains in planning practice. Planning Theory, 13(1): 5-25. http://doi.org/10.1177/1473095212469868

Chu, D., Strand, R. and Fjelland, R. 2003. Theories of complexity. Complexity, 8(3): 19-30. http://doi.org/10.1002/cplx.10059

Cook, A. P. and Lloyd, P. J. D. 2012. The estimation of greenhouse gas emissions from South African surface and abandoned coal mines. Journal of the Southern African Institute of Mining and Metallurgy, 112(12): 1087-1090.

Department of Energy. 2016. Coal procurement programme: Bid window 1 fact sheet. www.energy.gov.za/files/media/pr/2016/Coal-IPP-factsheet.pdf.

Department of Environmental Affairs of South Africa. 2017. Amendment of the environmental authorisa- 
tion issued on 31 October 2013 for the proposed construction of 450MW Khanyisa coal fired power station in Emalahlni, Mpumalanga Province.

Department of Environmental Affairs of South Africa. 2015. Amendment of the environmental authorisation issued on 31 October 2013 for the proposed construction of 450MW Khanyisa coal fired power station in Emalahlni, Mpumalanga Province.

Department of Environmental Affairs of South Africa. 2012. Integrated Environmental Authorisation, construction of 450MW Khanyisa coal fired power station and associated infrastructure in Emalahleni, Mpumalanga Province.

Department of Minerals and Energy. Undated. Independent Power Producer Procurement Programme. Accessed 22 October 2020. https://www.ipp-renewables.co.za/.

Fine, B. and Rustomjee, Z. 1996. The political economy of South Africa: From minerals-energy complex to industrialisation. London: Hurst and Company.

Fourie, D., Kritzinger-van Niekerk, L. and Nel, M. 2015. An overview of the renewable energy independent power producers procurement programme (REIPPPP. Energize RE: Renewable Energy Supplement, 15: 9-12

Global Energy Monitor Wiki. Accessed 22 September 2020. https://www.gem.wiki/Khanyisa_power_station.

Ismail, Z. and Khembo, P. 2015. Determinants of energy poverty in South Africa, Journal of Energy in Southern Africa, 26(3): 66-78. DOI: http://dx.doi.org/10.17159/2413-3051/2015/v26i3a2140

Kurtz, C. F. and Snowden, D. J. 2003. The new dynamics of strategy: Sense-making in a complex and complicated world. IEEE Engineering Management Review, 31(3): 110-130. http://doi.org/10.1109/EMR.2003.24944

Laisani, J. and Jegede, A. O. 2019. Impacts of coal mining in Witbank, Mpumalanga province of South Africa: An eco-legal perspective. Journal of Reviews on Global Economics, 8: 1586-1597.

McCall, B., Burton, J., Marquard, A., Hartley, F., Ahjum, F., Ireland, G., and Merven, B. 2019. Least-cost integrated resource planning and cost- optimal climate change mitigation policy: Alternatives for the South African electricity system. Energy Research Centre, University of Cape Town, Cape Town, South Africa. Retrieved from http://www.erc.uct.ac.za/sites/default/files/image_tool/ images/119/Papers-2019/Alt IRP final 07022019_2.pdf.

Mitleton-Kelly, E. 2015. Effective policy making: addressing apparently intractable problems. In P. Cairney and R. Geyer (Eds.), Handbook on complexity and public policy: 111-130. Cheltenham, United Kingdom: Edward Elgar.

Morin, E. 2006. Restricted complexity, general complexity. In Intelligence de la complexite: epitemologie et pragmatique: 1-25. Centre dEtudes Transdisciplinaires, Sociologie, Anthropologie, Histoire; Ecole des Hautes Etudes en Sciences Sociales.

National Planning Commission. 2011. South African National Development Plan 2030: Our future make it work. Pretoria, South Africa. Retrieved from http://www.npconline.co.za/MediaLib/Downloads/Downloads/NDP 2030 - Our future - make it work.pdf.

Patel, L. and Graham, L. 2012. How broad-based is broad-based black economic empowerment? Development Southern Africa 29(2): 193-207. DOI: 10.1080/0376835X.2012.675692

Price, J., Haynes, P., Darking, M., Stroud, J., Warren-Adamson, C. and Ricaurte, C. 2015. The policymaker's complexity toolkit. In R. Geyer and P. Cairney (Eds.), Handbook on complexity and public policy: 92-110. Cheltenham, United Kingdom: Edward Elgar.

Ptsera Environmental Management Consultants. 2011. Proposed independent coal fired power station with associated infrastructure in the eMalahleni area. Social impact assessment.

Republic of South Africa. 2011. National Climate Change Response White Paper. Pretoria, South Africa.

Republic of South Africa. 2004. Broad-Based Black Economic Empowerment Act, 2003. Government Gazette 463 (25899).

Richardson, K.A., Cilliers, P. and Lissack, M. 2001. Complexity science: A 'gray' science for the 'stuff in between'. Emergence, 3 (2): 6-18.

Savannah Environmental. 2017. Thabametsi power station near Lephalale, Limpopo Province: Climate change study and palaeontological impact assessment.

Shine, C. T. 2015. Policymaking as complex cartography? Mapping and achieving probable futures using complex concepts and tools. In P. Cairney \& R. Geyer (Eds.), Handbook on complexity and public policy: 171-189. Cheltenham, United Kingdom: Edward Elgar.

Stern, P. C., Sovacool, B. K. and Dietz, T. 2016. Towards a science of climate and energy choices. Nature Climate Change, 6(6): 547-555. http://doi.org/10.1038/nclimate3027 
Steyn, G., Burton, J. and Steenkamp, M. 2017. Eskom's financial crisis and the viability of coal-fired power in South Africa. Retrieved from http://meridianeconomics.co.za/wpcontent/uploads/2017/11/CoalGen-Report_FinalDoc_ForUpload-1.pdf.

Tyler, E. 2020. What might a Paris-aligned emissions profile look like for the South African power sector? Meridian Economics Policy Brief, July 2020/03.

Tyler, E and Steyn, G. 2018. Studying the employment implications of the South African power sector transition. Meridian Economics, Cape Town.

Voigt, C. and Ferreira, F. 2016. 'Dynamic differentiation': The principles of CBDR-RC, progression and highest possible ambition in the Paris Agreement. Transnational Environmental Law, 5(2): 285-303. https://doi.org/10.1017/S2047102516000212

Walby, S. 2007. Complexity theory, systems theory and multiple intersecting social inequalities in Philosophy of the Social Sciences 37 (4): 449-470. http://doi.org/10.1177/0048393107307663

Wells, J. 2013. Complexity and sustainability. Oxford: Routledge.

Wright, J., Bischof-Niemz, T., Calitz, J., Crescent, M., Robbie van, H. and Mamahloko, S. 2017. Council for Scientific and Industrial Research formal comments on the Integrated Resource Plan (IRP) Update Assumptions, Base Case and Observations 2016.

Yuen, K. 2014. REIPPPP - A new dawn for South African renewables? An analysis of renewable energy prices in the South AFrican Renewable Energy Independent Power Producer Programme. Masters Thesis Sciences Po, Paris School of International Affairs.

\section{Personal communications}

Burton, J. Researcher, Energy Research Centre, University of Cape Town, Cape Town. South Africa. 29 August 2018.

Govender, P. Executive Director of Business Development Phase of Khanyisa project. 26 February 2018.

Hallowes, D. Groundwork. 12 March 2018.

Loser, N. and Koyama, M. Centre for Environmental Rights. 19 February 2018.

Netch, A. Industrial Development Corporation. 27 February 2018. 